\title{
Evaluation of intubation condition following administration of rocuronium in comparison to atracurium in paediatric patients
}

\author{
Abdul Kuddus Khan ${ }^{*}$, MM Abdul Wadud², Azizul Gafur ${ }^{3}$, Rafayetullah Siddique ${ }^{4}$, \\ Debabrata Banik ${ }^{5}$
}

\begin{abstract}
${ }^{1}$ Assistant Professor, Department of Anaesthesiology, NICVD, Dhaka; ${ }^{2}$ Assistant Registrar, Department of Anaesthesiology, NICVD, Dhaka; ${ }^{3}$ Assistant Professor, Department of Anaestheiology, Jahurul Islam Medical College \& Hospital, Bajitpur, Kishoregonj, ${ }^{4}$ Assistant Professor, Dept. of Anaesthesia, Analgesia and Intensive Care Medicine, Bangabandhu Sheikh Mujib Medical University, Shahbag, Dhaka; ${ }^{5}$ Professor, Department of Anaesthesia, Analgesia and Intensive Care Medicine, Bangabandhu Sheikh Mujib Medical University, Shahbag, Dhaka.

*Corresponding author: drak_khannicvd@yahoo.com
\end{abstract}

\begin{abstract}
Background. Optimum intubation condition is paramount important for early and easy passage of endotracheal tube through the glottis and that results from adequate muscle relaxation. Rocuronium and atracurium are muscle relaxants used for short and intermediate duration of surgical processes.
\end{abstract}

Objective: This study, compares the intubation condition and haemodynamic changes in paediatric patients following administration of rocuronium and atracurium to get rid of the side effects of succinylcholine.

Method. The study was carried out in 60 patients aged $11 / 2$ to 10 years, ASA I-II, under general anaesthesia. The patients were divided into two groups: rocuronium $G r R$ and atracurium $G r A$. Induction was done with halothane $3.5-4 \%$ and for intubation rocuronium $0.6 \mathrm{mg} / \mathrm{kg}$ and atracurium $0.46 \mathrm{mg} / \mathrm{kg}$ were given to patients of $\mathrm{Gr} R$ and $\mathrm{Gr} A$ respectively. The intubation condition was assessed and gradded at 60 seconds after neuromuscular blocking agents. At the same time TOF ratios were recorded.

Results. Rocuronium produced good to excellent intubation condition (score $3.80 \pm 0.07$ ) in all patients at 60 seconds whereas that of atracurium poor intubation condition (score $2 \pm 0.00$ ). TOF ratios showed more relaxation of adductor pollicis muscle in $\mathrm{Gr} R$ than $\mathrm{Gr} A(G r R=60.43 \pm 0.87, \mathrm{Gr} A=78.90 \pm 0.72)$. $(p<0.001)$. Cardiovascular stability was not significantly difference in both the groups before induction and intubation.

Conclusion. Rocuronium produced better intubation condition in comparison to atracurium.

Keywords: Paediatric patients, intubation, rocuronium, atracurium

\section{Introduction}

In anaesthetic practice muscle relaxation is used to serve two prime purposes; one, to facilitate endotracheal intubation and the other to provide surgical relaxation ${ }^{1}$. Adequate muscle relaxation plays an important role in the concept of balanced anaesthesia ${ }^{2}$ and it demands for intubations to maintain artificial ventilation. Rapid sequence intubation is very important for paediatric patients because of their high metabolic rate, less functional residual capacity and more $\mathrm{O}_{2}$ requirement, during which there is a chance of hypoxia ${ }^{3}$.Children are more susceptible than adult to cardiac arrhythmias, hyperkalaemia, rhabdomyolysis, myoglobinemia, masseter spasm and malignant hyperthermia after succinylcholine administration. Unlike in adult patients, profound bradycardia and sinus node arrest develop in paediatric patients following the first does of succinylcholine without atropine pretreatment ${ }^{4}$.

Atracurium was developed in an attempt to obtain a non-depolarizing agent which had a more rapid onset, was shorter acting and had less 
cardiovascular effects than did the older agents but may release histamine and may be accompanied by a slight fall in arterial pressure ${ }^{5}$. Good to excellent intubating conditions after rocuronium $0.6 \mathrm{mg} / \mathrm{kg}$ obtained within 60 seconds when compared with vecuronium and atracurium in young children with intravenous anaesthetic agents $^{6}$. Aleksandra J. Mazurek et al.1998 found that rocuronium $(1.2 \mathrm{mg} / \mathrm{kg})$ can be substituted for succinylcholine during rapid sequence intubation in paediatric patients with intravenous anaesthetic agents ${ }^{7}$.The remarkable advantage of rocuronium is that one drug is used for intubation and maintenance of anaesthesia. Inspite of these advantages, this drug is not used in our daily practice. So, this study was done to determine and compare the intubation condition following administration of rocuronium and atracurium in paediatric patients combined with halothane induction with the aim of good to excellent intubation condition and reduction of intubation time.

\section{Subjects and methods}

This randomized prospective clinical study was carried out on sixty patients of both sex, aged between $1 \frac{1}{2}$ to 10 years for operations of an average duration of $1 / 2$ to 2 hours.

This study was approved by the ethical committee of the University and written informed consent was obtained from patients undergoing variety of surgical procedures requiring general anaesthesia. Patients were excluded if overweight, if they or their family had a history of neuromuscular diseases and if they received antibiotics before anaesthesia. Induction was done with halothane $3.5-4 \%$ and at the same time venous access was secured. Fentanyl was used $1.5 \mu \mathrm{gm} / \mathrm{kg}$ in both the groups. Rocuronium $0.6 \mathrm{mg} / \mathrm{kg}$ and atracurium $0.46 \mathrm{mg} / \mathrm{kg}$ were given to patients of $\mathrm{Gr} \mathrm{R}$ and $\mathrm{Gr}$ A respectively. Laryngoscopy was performed and intubation conditions were assessed and graded at 60 seconds after neuromuscular blocking agents using the 4 step scale proposed by Goldberg and his colleagues scoring system ${ }^{8}(4=$ excellent [easy passage of the tracheal tube without coughing, vocal cord relaxed], $3=$ good [slight coughing, vocal cord relaxed], $2=$ poor [ passage of the tracheal tube with moderate coughing, some movement of the vocal cord], and 1=impossible), and at the same time TOF ratios were recorded. TOF ratio indicates the degree of neuromuscular block. In the event of unsuccessful intubation ventilation was continued for another 30-45 sec until the next attempt was made. Pulse, mean arterial pressure, oxygen saturation were recorded just before induction, before intubation and after intubation. The results were compiled and analyzed statistically using unpaired Student's 't' test. P < 0.05 was considered as significant (by using SPSS version-12 software).

\section{Observation and Results}

There were no significant differences in the patients characteristics including age, weight and sex (Table I). Rocuronium produced $20 \%$ good and $80 \%$ excellent intubation condition. But atracurium produced poor intubation condition in all patients (Table II).

The mean \pm SEM values of intubation scores at 60 seconds were $3.80 \pm 0.07$ and $2 \pm 0.00$ in Gr R and Gr A respectively. They showed highly significant difference between the two groups(Table II). ( $p<$ 0.001).

The mean \pm SEM values of train of four ratio at 60 seconds were $60.43 \pm 0.87$ and $78.90 \pm 0.72$ in $\mathrm{Gr} R$ and Gr A respectively. They showed highly significant difference between the two groups(Table II). $(\mathrm{p}<0.001)$.

The mean \pm SEM values of heart rate, mean arterial pressures and oxygen saturation before induction were $103.33 \pm 3.29,78.03 \pm 0.64$ and 99.33 \pm 0.09 in $\mathrm{Gr} R$ and $97.13 \pm 0.96,78.53 \pm 0.59$ and $99.37 \pm 0.09$ in Gr A respectively. They showed no significant difference between the two groups (Fig. 1,2,3 and Table-III).

The mean \pm SEM values of heart rate, mean arterial pressures and oxygen saturation before intubation (when eye-lash reflex was lost), were $88.83 \pm 1.00,74.03 \pm 0.60$ and $99.40 \pm 0.09$ in $\mathrm{Gr} R$ and $86.80 \pm 1.06,72.90 \pm 0.56$ and $99.37 \pm 0.09$ in Gr A respectively. They showed no significant difference between the two groups (Fig.1,2,3 and Table-III).

The mean \pm SEM values of heart rate and mean arterial pressures after intubation were $103.33 \pm$ 1.37 and $78.47 \pm 0.65$ in Gr R and $115.80 \pm 1.53$ and $74.93 \pm 0.54$ in Gr A respectively. They showed 
highly significant difference between the two groups (Fig.1,2 and Table-III). ( $p<0.001)$.

The mean \pm SEM values of oxygen saturation after intubation were $99.47 \pm 0.09$ and $99.40 \pm 0.09$ in Gr R and Gr A respectively. They showed no significant difference between the two groups (Figure-3 Table-III). After discreet scrutiny it is revealed that before intubation oxygen saturation was a little bit less than after intubation in Gr A and it was due to poor intubation condition.

Table-I

Demographic characteristics of patients.

\begin{tabular}{lcccc}
\hline & $\begin{array}{c}\text { Age } \\
(\mathrm{yrs})\end{array}$ & $\begin{array}{c}\text { Weight } \\
(\mathrm{kg})\end{array}$ & Male & Female \\
\hline Gr R $(\mathrm{n}=30)$ & $5.20 \pm 0.48$ & $16.13 \pm 1.03$ & $19(63.3 \%)$ & $11(36.7 \%)$ \\
Gr A $(\mathrm{n}=30)$ & $5.55 \pm 0.41$ & $16.17 \pm 0.83$ & $18(60.0 \%)$ & $12(40.0 \%)$ \\
t-value & 0.551 & 0.025 & $37(61.7 \%)$ & $23(38.3 \%)$ \\
p-value & 0.584 & 0.980 & & \\
\hline
\end{tabular}

Values were expressed as Mean \pm SEM, values are regarded significant if $<0.05$.

Table II

Intubation Scores, Train of four ratios and intubation condition recorded at 60 seconds

\begin{tabular}{lccccc}
\hline & Intubation & Train of four & & \multicolumn{3}{c}{ Intubation condition } \\
\cline { 4 - 6 } & scores & ratios (T4/T1) & Poor & Good & Excellent \\
\hline Gr R $(\mathrm{n}=30)$ & $3.80 \pm 0.07$ & $60.43 \pm 0.87$ & & $20 \%=6$ & $80 \%=24$ \\
& & & & patients & patients \\
Gr A (n=30) & $2 \pm 0.00$ & $78.90 \pm 0.72$ & $\begin{array}{c}100 \%=30 \\
\text { patients }\end{array}$ & \\
t-value & 24.233 & 16.408 & & & \\
p-value & 0.001 & 0.001 & & & \\
\hline
\end{tabular}

Values were expressed as Mean \pm SEM, P $<0.001$ was considered as highly significant

Table III

Heart Rate, MAP ( $\mathrm{mm}$ of $\mathrm{Hg}$ ) and $\mathrm{SpO}_{2} \%$

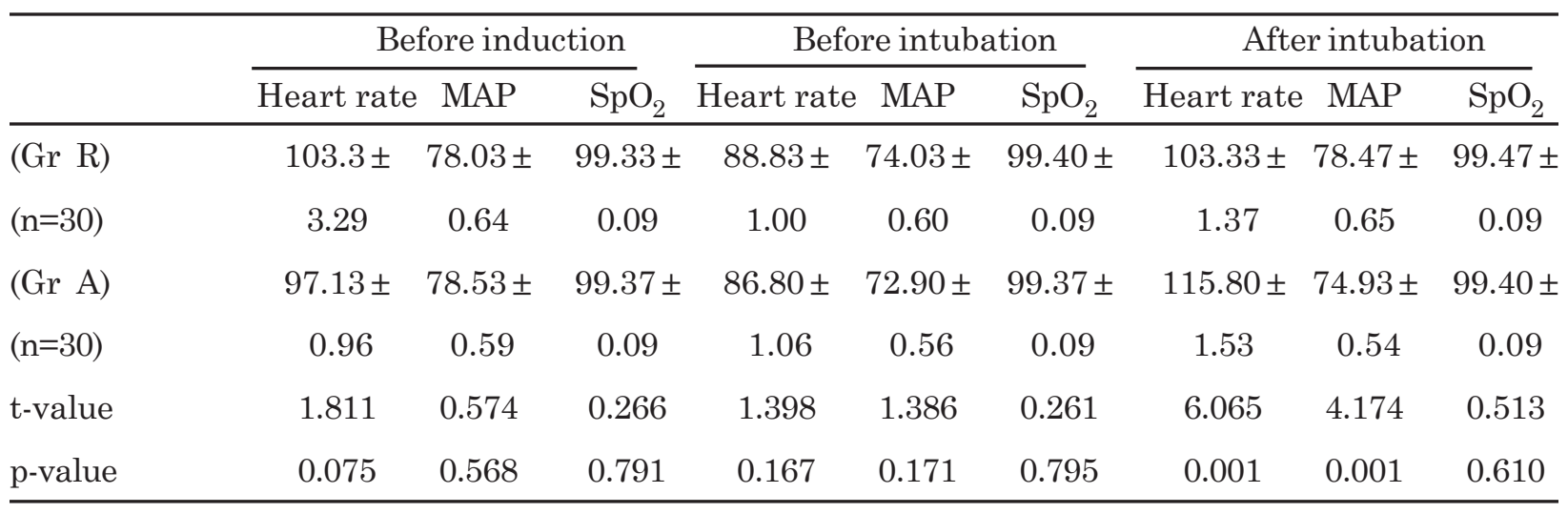

Values were expressed as Mean \pm SEM, $\mathrm{P}<0.001$ was considered as highly significant. 


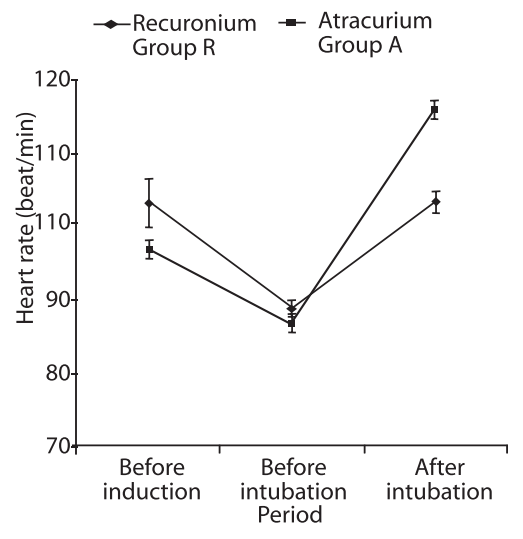

Fig.-1 : Changes of heart rate

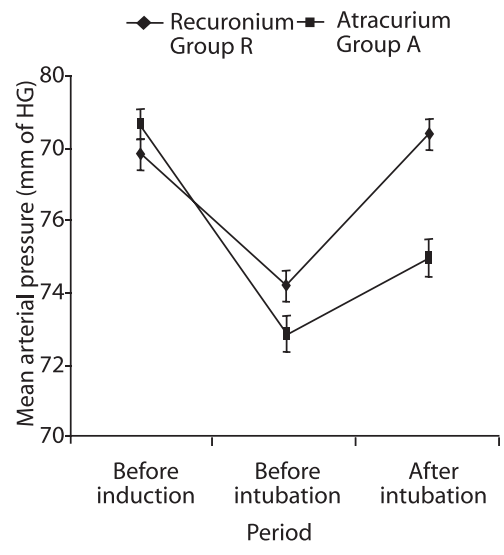

Fig.-2 : Changes in mean arterial pressure

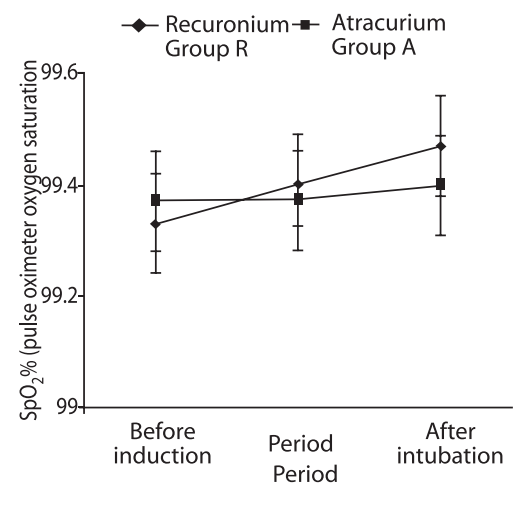

Fig.-3 : Changes in oxyten saturation

\section{Discussion}

Early intubation is a very essential part of general anaesthesia particularly in paediatric patients. Rocuronium is popular in adult patients but clinical experience is less in our country in paediatric patients.

Intubation was done at 60 seconds following administration of rocuronium $0.6 \mathrm{mg} / \mathrm{kg}$ and atracurium $0.46 \mathrm{mg} / \mathrm{kg}$, with $3.5-4 \%$ halothane as an induction agent in 50\% nitrous oxide and oxygen.

Rocuronium had shown $20 \%$ good and $80 \%$ excellent intubation conditions at 60 seconds whereas that of atracurium poor intubation condition in all patients.

Our study is supported by M. Bock et al. $2000^{9}$, Zhou et al. $2000^{10}$, Fuschs-Buder T and Tassonyi E, $1996^{11}$ and M. Eikermann et al. $2000^{12}$.

The mean \pm SEM values of train of four ratio at 60 seconds were $60.43 \pm 0.87$ and $78.90 \pm 0.72$ in Gr R and $\mathrm{Gr}$ A respectively. They showed highly significant difference between the two groups $(\mathrm{p}<0.001)$.

This result indicates that in our study the neuromuscular blockade at 60 seconds at the adductor pollicis muscle after rocuronium was greater than that of atracurium. TOF ratios are also comparable to intubation grading system. So, TOF ratios quantitatively supported the intubation condition in this study.

Mogorian et al.1993 and De Mey JC 1994, found in adults that the onset of neuromuscular blockade at the adductor pollicis muscle after rocuronium is more rapid compared with atracurium ${ }^{13}$. This finding is also comparable to present study.
Before induction and before intubation there was no significant difference between Gr R and Gr A in terms of heart rate, mean arterial pressure and oxygen saturation. The mean $\pm \mathrm{SEM}$ values of heart rate and mean arterial pressures after intubation were $103.33 \pm 1.37$ and $78.47 \pm 0.65$ in Gr R and $115.80 \pm 1.53$ and $74.93 \pm 0.54$ in Gr A respectively. They showed highly significant difference between the two groups $(p<0.001)$. The above findings are of rise of heart rate and fall of mean arterial pressure in the atracurium group and slight rise of heart rate, almost no change in mean arterial pressure in rocuronium group just after intubation. In case of atracurium increases of heart rate may be due to poor intubation condition ${ }^{14}$ and fall of blood pressure may be due to histamine release ${ }^{15}$.

It is also supported by Samia Elbaradie, 2004, and reported that following administration of $0.6 \mathrm{mg} /$ $\mathrm{kg}$ atracurium resulted with the decrease in mean arterial pressure and increase in heart rate ${ }^{16}$.

\section{Conclusion}

Our findings suggest that rocuronium is very much effective and produced good to excellent intubation condition at 60 seconds in paediatric patients.

\section{References}

1. Misra MN, Agarwal M, Pandey RP, Gupata A. A Comparative Study of Rocuronium, Vecuronium and Succinyl Choline for rapid sequence induction of anaesthesia. Indian J. Anaesth 2005; 49 (6): 469-473.

2. Foldes FF, Nagashima H,Nguyen HD, et al. The neuromuscular effects of ORG 9426 in patients receiving balanced anaesthesia. Anesthesiology 1991; 75: 191-6. 
3. Nunn JF.Nunn's applied respiratory physiology. Oxford: Butterworth-Heinemann Ltd. 1993. P

4. Morgan GE, Mikhail MS, Murray MJ Paediatric anaesthesia. Clinical Anesthesiology $3^{\text {rd }}$ edition. New York: The Mc Graw-Hill, 2002; 849-858.

5. Aitkenhead AR, Rowbotham DJ, Smith G. 'Textbook of Anaesthesia'. Fourth Edition, New York: Churchill Livingstone; 2001.

6. Gerd S, Flavio CR, Albert, et al. Intubating conditions and onset of action after rocuronium, vecuronium, and atracurium in young children anesth analg 1996; 83: 320-4.

7. Mazurek AJ, Rae B, Hann S, Kim JI, et al. Rocuronium versus succinylcholine are they equally effective during rapid sequence induction of anaesthesia? Anesth Analg 1998; 87:1259- 62 .

8. Goldberg ME, Larijani GE, Azad SS, et al. Comparison of tracheal intubating conditions and neuromuscular blocking profiles after intubating doses of mivacurium chloride or succinylcholine in surgical patients. Anesth Analg 1989; 69: 93-9.

9. Bock M, Klippel K, Nitsche B, et al. Rocuronium potency and recovery characteristics during steady-state desflurane, sevoflurane isoflurane or propofol anaesthesia. Br J Anaesth 2000; 84 (1): 43-7.

10. Zhou TJ, White PF, Chiu JW, et al. Onset/ offset characteristics and intubating conditions of rapacuronium: a comparison with clinical investigation'. Br J Anaesth 2000; 85: 246250.

11. Fuchs-Buder T, Tassonyi E. Intubating conditions and time course of action of rocuronium-induced neuromuscular block in children. Br J Anaesth 1996; 77: 335-8.

12. Eikermann M, Hunkemoller I, Peine L et al. Optimal rocuronium dose for intubation during inhalation induction with sevoflurane in children. Br J Anaesth 2002; 89 (2): 277-81.

13. Magorian T, Flannery KB, Miller RD. Comparison of rocuronium, succinylcholine and vecuronium for rapid- sequence intubation of anaesthesia in adult patients. Anesthesiology 1993; 79: 913-8.

14. Naguib M, Samarkandi AH, Bakhamees HS, et al. Histamine-release haemodynamic changes produced by rocuronium, vecuronium, mivacurium, atracurium and tubocurarine. Br J Anaesthesia1995; 75: 58892.

15. Savarese JJ, Ali HH, Basta SJ, et al. The cardiovascular effects of mivacurium chloride (BW B1090U) in patients receiving nitrous oxide-opiate-barbiturate anesthesia. Anesthesialogy 1989; 70: 386-394.

16. Elbaradie S. Neuromuscular efficacy and histamine-release hemodynamic changes produced by rocuronium versus atracurium: A comparative study. Journal of the Egyptian Nat. Cancer Inst., 2004; 16: 107-113. 